\title{
ON QI-ALGEBRAS
}

\author{
RAVI KUMAR BANDARU \\ Department of Engineering Mathematics, GITAM University \\ Hyderabad Campus, Telangana, 502 329 India \\ e-mail: ravimaths83@gmail.com
}

\begin{abstract}
In this paper, the notion of a QI-algebra is introduced which is a generalization of a BI-algebra and there are studied its properties. We considered ideals, congruence kernels in a QI-algebra and characterized congruence kernels whenever a QI-algebra is right distributive.
\end{abstract}

Keywords: BI-algebra, QI-algebra, right distributive, ideal, congruence kernel.

2010 Mathematics Subject Classification: 06F35, 20 N02.

\section{REFERENCES}

[1] A.B. Saeid, H. Sik Kim and A. Rezaei, On BI-algebras, An. Şt. Univ. Ovidius Constanţa 25 (2017) 177-194.

doi:10.1515/auom-2017-0014

[2] J.C. Abbott, Semi-bolean algebra, Matem. Vestnik 4 (1967) 177-198. http://eudml.org/doc/258960

[3] Y. Imai and K. Isaeki, On axiom systems of propositional calculi, XIV, Proc. Japan Acad. 42 (1966) 19-22. doi:10.3792/pja/1195522169

[4] I. Iseki and S. Tanaka, An introduction to the theory of BCK-algebras, Math. Japon. 23 (1978) 1-26.

[5] I. Iseki, On BCI-algebras, Mathematics Seminar Notes 8 (1980) 125-130. http://www.math.kobe-u.ac.jp/jmsj/kjm/

[6] W.Y. Chen and J.S. Oliveira, Implication algebras and the metropolis rota axioms for cubic lattices, J. Algebra 171 (1995) 383-396. doi:10.1006/jabr.1995.1017 
